Revista Destaques Acadêmicos, Lajeado, v. 12, n. 2, 2020. ISSN 2176-3070

DOI: http://dx.doi.org/10.22410/issn.2176-3070.v12i2a2020.2620

http://www.univates.br/revistas

\title{
MILITARIZAÇÃO DA ESCOLA PÚBLICA: UMA REFLEXÃO HISTÓRICA DO SISTEMA EDUCACIONAL BRASILEIRO E DAS LUTAS EM MATO GROSSO
}

\author{
Monica Strege Medici ${ }^{1}$, Domenico dos Santos Medici ${ }^{2}$, Marcelo Franco Leão ${ }^{3}$
}

Resumo: Atualmente, é crescente a onda de ataques à escola pública brasileira. A mais recente estratégia de ataque aos princípios da democracia, da autonomia e da criticidade da escola é a defesa da militarização das escolas públicas, como se fosse a solução para sanar os problemas da educação, tais como a violência e os baixos índices de aproveitamento. $\mathrm{O}$ estudo teve como objetivo realizar uma reflexão histórica sobre como esse preocupante fenômeno vem acontecendo no Sistema Educacional Brasileiro, bem como sobre as recentes lutas em torno da militarização que aconteceram em Mato Grosso. Trata-se de um estudo teórico, embasado na legislação brasileira, que discorre sobre a implantação do sistema de educação. Realizamos um retrospecto histórico das mudanças na estrutura e organização das escolas brasileiras, bem como levantamento das principais diferenças de objetivos da escola pública atual, pautada na gestão democrática e pluralismo de ideias, e a escola cívico-militar, pautada na disciplina e na ordem. Este estudo finaliza com o relato e reflexão dos últimos acontecimentos de lutas contra esses ataques à educação, em especial o enfrentamento à Lei de $n^{\circ}$ 10.922/2019, do Estado de Mato Grosso, que idealiza militarizar escolas públicas já existentes.

Palavras-chave: Autonomia. Educação transformadora. Escola cívico-militar.

1 Graduação em Licenciatura em Ciências Biológicas e Bacharel em Ecologia (Centro Universitário de Várzea Grande). Especialização em Ensino de Biologia (Universidade Candido Mendes). Professora efetiva na Escola Estadual Professora Maria Esther Peres (SEDUC/MT), onde ministra as disciplinas de ciências e biologia para o Ensino Fundamental e Médio. Membro do Grupo de Pesquisa Ensino de Ciências e Matemática no Baixo Araguaia (EnCiMa).

2 Graduação em Educação Física (Centro Universitário de Volta Redonda). Especialização em Educação Física Escolar (Associação Darwin de Educação e Pesquisa). Professor efetivo na Escola Estadual Professora Maria Esther Peres (SEDUC/MT), onde ministra as aulas de Educação Física para o Ensino Fundamental e Médio.

3 Graduação em Química Licenciatura Plena (UNISC) e em Licenciatura em Física (UNEMAT). Especialização em Orientação Educacional (DOM ALBERTO) e em Relações Raciais e Educação na Sociedade Brasileira (UFMT). Mestrado em Ensino (UNIVATES) e Doutorado em Educação em Ciências: Química da Vida e Saúde (UFRGS). Professor de Química no Departamento de Ensino do IFMT Campus Confresa. Membro do Grupo de Pesquisa Ensino de Ciências e Matemática no Baixo Araguaia (EnCiMa). 


\section{INTRODUÇÃO}

Um fenômeno atual preocupante é a crescente onda de ataques à escola pública brasileira, seja pela desvalorização dos profissionais da educação, precarização das condições físicas e materiais ou ainda pelo ataque ideológico e de descrédito da instituição educativa que alguns políticos lançam para a opinião pública.

A mais recente estratégia de ataque aos princípios da democracia, da autonomia e da criticidade da escola é a defesa da militarização das escolas públicas, como se fosse a solução para sanar os problemas da educação, tais como a violência e os baixos índices de aproveitamento. Diante da perspectiva de buscar mudanças no sistema educacional, é importante refletir sobre a atual conjuntura educacional, suas fragilidades e fazer uma avaliação global no sentido de identificar seus principais desafios. Dessa forma, será possível propor mudanças que propiciem resultados efetivos para a sociedade, onde filhos e filhas de trabalhadores tenham acesso a mesma educação de qualidade ofertada aos filhos da elite. A tendência em militarizar escolas advém de um projeto do governo atual que propõe a militarização das escolas como a "tábua de salvação" da sociedade. Nessa linha de pensamento, todo o legado da educação brasileira passa a ser desconsiderado em detrimento de uma "nova escola", que corrobore para a criação de uma nova conjuntura social, pautada em valores patrióticos e cristãos.

Contrapondo a este projeto, nas últimas décadas temos um crescimento significativo de iniciativas envolvendo a educação popular, movimentos estes nunca vistos antes na história da educação brasileira. Essa universalização da educação, não só no acesso mas também na própria finalidade de formação integral, começou a ser defendida pela Lei de Diretrizes e Bases da Educação Nacional (BRASIL, 1996), que propõe temas transversais voltados à diversidade social ampliando o olhar da educação para diversos aspectos sociais que influenciam na formação do sujeito.

As políticas públicas das últimas décadas promoveram a inserção de todos na escola e com isso propiciaram a ascensão social de muitos filhos e filhas de trabalhadores que não tiveram acesso as escolas.

Frente ao exposto, este estudo tem como objetivo realizar uma reflexão histórica sobre como esse preocupante fenômeno vem acontecendo no Sistema Educacional Brasileiro, bem como sobre as recentes lutas em torno da militarização que aconteceram em Mato Grosso.

Trata-se de um estudo teórico, embasado na legislação brasileira que discorre sobre a implantação do sistema de educação; Propomos um retrospecto histórico das mudanças na estrutura e organização das escolas brasileiras e destacamos, ainda as principais diferenças de objetivos da escola pública atual, pautada na gestão democrática e pluralismo de ideias, e a escola cívico-militar, pautada na disciplina e na ordem. O presente estudo finaliza com o relato e 
reflexão dos últimos acontecimentos de lutas contra esses ataques à educação, em especial o enfrentamento à Lei de n ${ }^{\circ}$ 10.922/2019, do Estado de Mato Grosso, de autoria do Deputado Estadual Silvio Favero (PSL), que idealiza militarizar escolas públicas já existentes.

\section{BREVE HISTÓRICO DO SISTEMA EDUCACIONAL BRASILEIRO}

A educação brasileira apresenta nuances que precisam ser consideradas para que possamos avaliar sua efetividade. A começar pela análise geográfica do país, segundo Figueiredo (2016, p. 11): "Quinto país em extensão territorial do planeta, com uma superfície de $8.515 .767 .049 \mathrm{~km}^{2}$, o Brasil ocupa quase a metade do continente sul-americano, possuindo uma vasta região fronteiriça com todas as nações da América do Sul, à exceção do Chile e do Equador".

Conforme o trecho acima, a extensão territorial do estado brasileiro é vasta e sobretudo diversa em função de sua colonização e de suas áreas fronteiriças o que facilita o intercâmbio cultural e a construção da identidade cultural de uma forma regional. Isso se constitui um desafio para processo educacional, no sentido de não ser possível homogeneizar o sistema por meio de um único método. Abicalil (2012) afirma que o país possui 27 sistemas estaduais de ensino, incluído o do Distrito Federal, o próprio sistema federal de ensino e, no limite, 5.565 sistemas municipais de ensino, supostamente autônomos entre si. Nessa linha de pensamento, a educação brasileira não é uniformizada, aspectos sociais precisam ser considerados para que possamos avaliar sua efetividade. Agregada à análise geográfica do Brasil, temos um país com imensas desigualdades sociais acentuadas principalmente nas regiões periféricas.

Fazendo uma retomada histórica do sistema educacional brasileiro, por volta de 1540, temos o seu início, de forma rudimentar, quando os jesuítas comandados pelo espanhol Inácio de Loyola, fundaram a Companhia de Jesus com o intuito de catequizar os povos nativos (PAIVA, 2000).O autor acredita que este foi um modelo de educação voltado para a sociedade portuguesa quinhentista, sendo que o fator determinante da cultura portuguesa da época era a sacralidade da sociedade, ou seja, no centro da sociedade existia uma divindade e a sociedade se organizava em torno disso..

Ainda de acordo com Paiva (2000, p. 57), “Todos realizavam, no que lhes era próprio, o reino de Deus: o rei governando, o padre rezando, o soldado guerreando, o comerciante tratando, a mulher guardando a casa. Nada havia que não pertencesse à esfera do sagrado, tal como era compreendido".

Conforme o autor supracitado, todos os agentes sociais precisavam seguir a doutrina que submetia todos a Deus e respectivamente ao rei. Esta foi a primeira experiência brasileira de implantação de um sistema educacional à luz dos princípios religiosos o que mais tarde Freire (2001, p. 28), denominou a colonização de mentes. Segundo Freire, os jesuítas foram "Docilizando a 
população nativa (gentio) e os filhos dos colonos através da domesticação, da repressão cultural e religiosa, os jesuítas serviram à empresa exploradora lusa com a visão maniqueísta do mundo."

A educação jesuíta, que perdurou cerca de 2 séculos, deixou seu legado na história do sistema educacional brasileiro. Como os jesuítas precisavam estabelecer recursos de comunicação com os indígenas, implantaram o processo de alfabetização seguindo os princípios da conversão cristã e avesso à liberdade instituíram um modelo de ensino uniforme em face ao movimento iluminista que começava a irradiar-se pelo mundo. O sistema jesuítico passou a receber críticas por implantar um sistema cristalizado. Nas palavras de Saviani (2007, p. 80):

Defendiam o desenvolvimento cultural do Império português pela difusão das novas ideias de base empirista e utilitarista; pelo "derramamento das luzes da razão nos mais variados setores da vida portuguesa; mas voltaram-se especialmente para a educação que deveria ser libertada do monopólio jesuítico, cujo ensino se mantinha, conforme entendiam, preso a Aristóteles e avesso aos métodos modernos de fazer ciência."

Saviani (2007) ainda afirma que durante o reinado de Dom João V começaram emergir muitas pressões por reformas no plano político, mas só se concretizaram quando Dom José I chega ao trono, em 1750, e a efetiva a nomeação de Pombal como seu primeiro ministro. Após uma incursão diplomática pela Inglaterra em 1744, na Áustria, de onde volta para Portugal levando elementos experienciais que a Áustria havia implantado no campo educacional, submetendo a educação à políticas de Estado e afastando-a da influência da Igreja. Marquês de Pombal avança então com seu projeto de revolução do sistema educacional desvinculando-o da igreja. No estudo de Shigunov Neto e Maciel (2008), verifica-se que o ensino jesuítico no Brasil foi extinto por Marquês de Pombal, por destoar dos interesses da coroa portuguesa da época. Nas palavras dos autores:

A Companhia de Jesus teve suas atividades suspensas na Colônia brasileira a partir de 1759, com o Decreto-lei de 3 de setembro de 1759 promulgado pelo Rei D. José I. Com a promulgação da lei, o Ministro de Estado, Marquês de Pombal, exilava de Portugal e da Colônia brasileira a Companhia de Jesus, confiscando para a Coroa portuguesa todos os seus bens materiais e financeiros (SHIGUNOV NETO; MACIEL, 2008, p. 177).

Após a ruptura do ensino ofertado pela Companhia de Jesus na então colônia brasileira, inicia-se uma reforma educacional no Brasil. Ledesma (2010), afirma que o período entre 1759 a 1772, teve como Diretor Geral de Estudos Dom Tomás de Almeida, o qual se tornou fundamental para estatizar os 
Estudos dessa primeira fase da reforma pombalina. Esse processo consistiu em reformular o sistema por meio de reforma curricular, nomeação de comissários de estudos, livros permitidos as aulas regias e a elaboração de concursos para professores régios aqueles nomeados pelo rei.

As aulas eram ofertadas na casa do professor ou nas antigas instalações jesuítas. Ledesma (2010, p. 30) ressalta que houve um lapso de 13 anos entre a expulsão dos jesuítas até a reforma pombalina chegar ao Brasil. Apenas em 1722 uma ordem régia estabeleceu, no Rio de Janeiro e na primeiras cidades do Brasil, aulas de Primeiras Letras, de gramática, de latim e de grego, impondo assim o "subsidio literário" por meio de imposto que deveria prover a educação em Portugal e na Colônia.

Esta reforma foi implantada com inúmeros desafios, entre eles o financiamento dos custos da educação pela coroa portuguesa, com objetivos claros de fortalecer a submissão da colônia brasileira ao império português. Freire (2001) destaca a proibição da fala da língua nativa - o tupi - no Brasil, em 1727, pelo governo português. Proibindo aqueles que aqui encontraram de falar sua própria língua, e sua cultura para impor os valores do colonizador, percebemos uma verdadeira invasão cultural, também apontada por Freire (2005).

Mesmo 300 anos após a chegada dos portugueses no Brasil, o país não havia consolidado seu sistema educacional e uma intervenção externa provocou mudanças, as tropas de Napoleão Bonaparte invadem Portugal e a família real vieram para o Brasil e o sistema educacional passou a ser reformulado. No entanto, nos deparamos com o fato de que ao implantar o sistema educacional brasileiro, pautado na segregação, apenas os filhos da elite tinham acesso à escola, pois a consolidação da educação oportunizava a participação na política. Assim, ao longo do tempo as desigualdades sociais foram se acentuando, pois a escola era para um grupo restrito.

Melo (2012) destaca que a Primeira República foi marcada por conflitos políticos, sociais e educacionais e a classe média cada vez mais desprezada passa a promover movimento populares reivindicando principalmente o fim do voto de cabresto visando o rompimento do elo político entre os estados que detinham o domínio sócio-político e econômico do Brasil. O autor ressalta ainda que neste período a educação era pensada para a elite, o número de vagas era reduzido e as teorias aplicadas seguiam os modelos europeus.

O acesso à escola foi ampliado para a sociedade por volta de 1870 . Nesse período, insere-se na sociedade brasileira o ideário pedagógico voltado para as práticas educativas escolares objetivando um padrão de modernização da sociedade. Cabe ressaltar que nessa época, o Brasil vivenciava profundas mudanças de cunho político, social, econômico e cultural e deste modo temos uma realidade voltada para a ampliação das escolas e a formação docente, que aconteceu entre as últimas décadas do século XVIII e início do século XIX, (verificar a data, pois constava uma data não válida) com o propósito de 
expandir o acesso à educação a todos inclusive àqueles que não tiveram acesso à escola até então, pois, como destaca Ghiraldelli Jr. (2003), o período militar deixou um legado de desmonte do sistema educacional brasileiro.

De acordo com Ghiraldelli Jr. (2003, p. 125):

A educação se pautou pela repressão, privatização do ensino, exclusão de boa parcela dos setores mais pobres do ensino elementar de boa qualidade, institucionalização do ensino profissionalizante na rede pública regular sem qualquer arranjo prévio para tal feito, divulgação de uma pedagogia calcada mais em técnicas do que em propósitos com fins abertos e discutíveis, várias tentativas de desmobilização do magistério através de abundante e não raro confusa legislação educacional. Somente uma visão bastante condescendente com os ditadores poderia encontrar indícios de algum saldo positivo na herança deixada pela ditadura militar.

Tendo em vista a situação da educação brasileira, foi necessário construir leis que pudessem amparar a redemocratização do ensino, uma vez que o legado militar foi a desconstrução do movimento escolanovista. Esse movimento educacional aconteceu por volta de 1930, surgindo em diversos países, tais como: Inglaterra, Alemanha, Áustria, França, Suíça, Espanha, Estados Unidos da América e no Brasil, dentre outros. No Brasil reuniram-se intelectuais, educadores e políticos que elaboraram um manifesto. Para Vidal (2013), o manifesto era baseado nos pilares sociais com propósito de ampliação da educação a toda sociedade.

Inicialmente, efetuava a defesa de princípios gerais que, sob a rubrica de novos ideais de educação, pretendiam modernizar o sistema educativo e a sociedade brasileira. Além da laicidade, da gratuidade, da obrigatoriedade e da coeducação, o Manifesto propugnava pela escola única, constituída sobre a base do trabalho produtivo, tido como fundamento das relações sociais, e pela defesa do Estado como responsável pela disseminação da escola brasileira. Nesse sentido, distinguia-se do que denominava educação tradicional, particularmente no que considerada como a maior contribuição da Escola Nova: a organização científica da escola (VIDAL, 2013, p. 579).

Com base nos princípios da defesa da educação popular, pautada na defesa de uma escola pública de qualidade para todos, era necessário garantir que esta escola fosse laica e também obrigatória para que as classes trabalhadoras tivessem acesso à escola. $\mathrm{O}$ estado deveria garantir que o sistema educacional fosse um território laico considerando as dimensões e a multiculturalidade do país. Neste contexto, se destacam importantes nomes como Anísio Teixeira, Fernando de Azevedo e Lourenço Filho, suas ideias convergiam e propunham realizar a reconstrução social pela reconstrução educacional, que tinha por 
princípio a laicidade, gratuidade, obrigatoriedade, coeducação e a unidade da escola. Saviani (2006) destaca que essa vertente pedagógica, parte do pressuposto que a educação é função do Estado em todas suas instâncias, graus ou estágio de ensino.

O Manifesto apresenta-se, pois, como um instrumento político, como é o próprio, aliás, desse "gênero literário". Expressa a posição do grupo de educadores que se aglutinou na década de 1920 e que vislumbrou na Revolução de 1930 a oportunidade de vir a exercer o controle da educação no país [...]. Pode, pois, ser considerado um importante legado que nos é deixado pelo século XX. É um marco de referência que inspirou as gerações seguintes, tendo influenciado, a partir de seu lançamento, a teoria da educação, a política educacional, assim como a prática pedagógica em todo o país (SAVIANI, 2006, p. 34-35).

$\mathrm{O}$ autor ressalta que o manifesto representou mais que um ideal de defesa da escola nova, pois contribuiu com as reflexões para defesa de uma escola pública. Nesse sentido, Saviani (2006) considera o Manifesto como um grande legado do século XX que, apesar dos esforços dos educadores, não teve concretização no país. O movimento promoveu a democratização do ensino incluindo os adultos que não tiveram acesso à educação. Este período foi muito significativo, pois existia uma grande demanda de estudantes e poucos profissionais aptos a lecionar. A ampliação dos cursos de formação de professores favoreceu a expansão do movimento.

No entanto, durante o período de 1964 a 1985 o Brasil foi submetido a Ditadura Militar, um tempo antidemocrático, no qual os militares assumiram politicamente o país, comandando as mais diversas áreas, inclusive a Educação. É triste lembrar que nessa época houve censura, repressão ideológica, autoritarismo, torturas e perseguições políticas. As escolas foram utilizadas pelos militares como um aparelho ideológico essencial para apresentar à população a ideia de que o país estava no rumo certo e assim obter êxito na dominação, (não dá pra saber a quem se refere esse trecho "sem serem questionados") visando a educação tecnicista. Veiga (1989) destaca que:

O modelo político econômico tinha como característica fundamental um projeto desenvolvimentista que busca acelerar o crescimento socioeconômico do país. A educação desempenhava importante papel na preparação adequada de recursos humanos necessários à incrementação do crescimento econômico e tecnológico da sociedade de acordo com a concepção economicista de educação (VEIGA, 1989, p. 34).

Nesse período, as escolas brasileiras passaram a adotar metodologias tradicionalistas centradas no professor, geralmente militar. Na época, o objetivo 
da educação era preparar a mão de obra, voltada para o contexto econômico e tecnológico. Assim, não era interessante que o estudante tivesse pensamento crítico, a ele cabia apenas ouvir passivamente e apresentar uma "boa conduta" pautada na disciplina, nos valores morais e patrióticos. Por isso, o professor era a figura central, sempre tinha razão e não estava sujeito a questionamentos. Ao

Nessa perspectiva, fica evidente o domínio ideológico, pois:

As matérias de estudo visam preparar o aluno para a vida, são determinadas pela sociedade e ordenadas na legislação. Os conteúdos são separados da experiência do aluno e das realidades sociais, valendo pelo valor intelectual, razão pela qual a pedagogia tradicional é criticada como intelectualista e, às vezes, como enciclopédica. [...] A ênfase nos exercícios, na repetição de conceitos ou fórmulas na memorização visa disciplinar a mente e formar hábitos. [...] Predomina a autoridade do professor que exige atitude receptiva dos alunos e impede qualquer comunicação entre eles no decorrer da aula. O professor transmite o conteúdo na forma de verdade a ser absorvida; em consequência, a disciplina imposta é o meio mais eficaz para assegurar a atenção e o silêncio (LUCKESI, 1994, p. 56-57).

Desse modo, a escola passa a ser vista como um ambiente que propaga valores e disciplina desconsiderando a natureza humana movida pela capacidade de questionar-se e questionar o mundo onde está inserido. A educação neste período foi marcada pela formatação do pensamento destacada pelas práticas repetitivas e a exigência de decorar conceitos e não os construir, a seleção de conteúdos não estimulava a reflexão crítica, tampouco a emancipação do sujeito.

Crítico a este movimento e engajado nos movimentos de cultura popular, Paulo Freire, educador renomado, na época conhecido por promover uma educação critico-reflexiva e emancipadora, manifestou-se contrário a este método e o denominou de "educação bancária". Segundo Freire, a educação bancária considera o estudante como "vaso vazio", onde o professor "deposita" conteúdo.

Desafiado pela educação, Paulo Freire desenvolveu um método para a alfabetização de adultos sobre a perspectiva do diálogo, da conversa e da conscientização baseado nas palavras geradoras advindas do cotidiano do estudante. Freire (2001, p. 57), afirma que:

Me parece fundamental, neste exercício, deixar claro, desde o início, que não pode existir uma prática educativa neutra, descomprometida, apolítica. A diretividade da prática educativa que a faz transbordar sempre de si mesma e perseguir um certo fim, um sonho, uma utopia, não permite sua neutralidade. A impossibilidade de ser neutra não tem nada que ver com a arbitrária 
imposição que faz o educador autoritário a "seus" educandos de suas opções.

Em 1963, na cidade de Angicos, no Rio Grande do Norte, Paulo Freire, juntamente com sua equipe, conseguiu alfabetizar 300 trabalhadores em 40 horas, reinventou a educação do ponto de vista da relação professor e estudante. Conhecido nacionalmente, Freire passa a coordenar o plano nacional de educação a experiência vivida em Angicos desperta o interesse do mundo em relação ao método freiriano (GERMANO, 1997).

Fazer com que os participantes aprendessem a ler e a escrever e, ainda por cima, viessem a se politizar em 40 horas constituíam os objetivos fundamentais da experiência. Isso despertou enorme curiosidade, motivo pelo qual o trabalho de Freire e dos estudantes do Rio Grande do Norte correu o mundo. Em Angicos estiveram presentes observadores, especialistas em educação e jornalistas não somente dos principais meios de comunicação do Brasil, como do exterior. Para lá se deslocaram, por exemplo, representantes do New York Times, do Time Magazine, do Herald Tribune, do Sunday Times, do United e da Associated Press, do Le Monde. Finalmente, o próprio presidente João Goulart, junto com Aluizio Alves, governador do Rio Grande do Norte, compareceu ao encerramento das atividades dos Círculos de Cultura, na distante data de 2 de abril de 1963 (GERMANO, 1997, p. 389).

Após o golpe, os militares passaram a atacar Paulo Freire, que foi perseguido e preso, e logo após buscou exílio em princípio na Bolívia, em seguida foi para outros países. Germano (1997, p. 391) ainda ressalta:

Começa aí o périplo de Freire pelo mundo, tendo percorrido mais de 50 países, lecionado nos mais importantes centros universitários internacionais, como a Universidade de Harvard, e aplicado o seu método de alfabetização em nações da Ásia, da África e da América Latina. A sua obra acabou, portanto, por assumir dimensões universais (GERMANO, 1997, p. 391).

Com o cerceamento da pedagogia crítica, iniciou-se uma nova visão sobre a educação brasileira partindo da concepção militar. No entanto, o legado da ditadura militar para a educação brasileira foi bastante impactante, pois disciplinas que estimulavam o pensamento crítico como filosofia e sociologia foram abolidas da grade curricular e os conteúdos programáticos eram fiscalizados, diversos conteúdos das disciplinas de história e geografia foram abolidos dos livros didáticos. "Promoveram a criação das famosas disciplinas Organização Social e Política Brasileira (OSPB) e Educação Moral e Cívica, trazidas pela ditadura com o decreto-lei número 869 , de 12 de setembro de 1969" (DUARTE, 2014, p. 1). 
Neste período, os saberes docentes nem sempre eram valorizados, pois para lecionar não era necessário formação, o que contribuiu com a desvalorização da carreira docente. Vicentini e Lugli (2009, p. 222-223) afirmam que:

Não se pode deixar de mencionar os efeitos da ditadura militar (19641985) sobre a docência. Nesse período houve uma visível deterioração no sistema de ensino público, identificada pelo excessivo número de professores trabalhando em caráter precário (os antigos estagiários) para compensar a falta de profissionais efetivados. Os substitutos muitas vezes não tinham formação pedagógica [...] as relações pedagógicas se construíam de forma efêmera e pouco produtiva, impondo inegáveis dificuldades aos resultados do trabalho escolar (VICENTINI; LUGLI 2009, p. 222-223).

A desvalorização da carreira docente contribui para o declínio da qualidade de ensino público em âmbito nacional. A precarização do ensino contribuiu para a marginalização e consequente aumento das desigualdades sociais, que ficaram cada vez mais evidentes no país sob o comando dos militares que promoveram uma educação popular voltada apenas para a produção de mão-de-obra tecnicista, visando a entrada de capital estrangeiro e a industrialização do país deste modo mantem a estratificação social.

Por volta dos anos 80, o militarismo enfraqueceu e passou a emitir os primeiros sinais de sua queda após o período militar, que durou mais de duas décadas (1964 a 1985). Houve a eleição de Tancredo Neves, seguida de sua morte, motivo que levou o seu vice, José Sarney ao poder. Esse marco pôs fim a 21 anos de regime de repressão, período demarcado por censura, perseguição política, supressão de direitos constitucionais e a repressão àqueles que eram contrários ao regime (VICENTINI; LUGLI 2009). Deu-se então, o início a um intenso debate sobre a necessidade de convocação de uma Assembleia Constituinte, de modo a reestabelecer a democracia no País. A Constituinte foi instalada no Congresso Nacional, em Brasília, no dia $1^{\circ}$ de fevereiro de 1987 com a finalidade de elaborar uma Constituição democrática para o país.

O sistema educacional brasileiro foi praticamente reconstruído a partir da elaboração constituição de 1988. Considera-se o documento como um marco civilizatório para reformular a educação, pois garante a liberdade de expressão e direitos sociais considerados fundamentais a cada cidadão brasileiro ou naturalizado. Ao definir a educação como direito social de todos, inclusive dos que não tiveram acesso na idade adequada, a Constituição Federal de 1988, definiu de quem seria a responsabilidade pela garantia deste direito. Assim, o Art. 205, define que o dever de garantir o direito à educação é do Estado e da família, os quais deverão promovê-la e incentivá-la, com a colaboração da sociedade. Define, ainda, que a educação a ser ofertada objetiva o "pleno 
desenvolvimento da pessoa, seu preparo para o exercício da cidadania e sua qualificação para o trabalho" (BRASIL, 1988).

Mesmo tendo enfrentado importantes desafios, o sistema educacional brasileiro sempre teve seus defensores que lutaram incansavelmente para garantir educação pública de qualidade para todos. A implantação e reformulação no sistema de ensino não foi ofertado por nenhum governo mas devido aos intensos movimentos de luta por todos aqueles que defendem a democratização da educação de qualidade como um mecanismo capaz de promover equidade social. Santos e Pereira (2018, p. 256), afirmam que:

Se os chamados anos de chumbo foram demarcados pelo cerceamento de direitos fundamentais, como a liberdade de expressão e de organização, com supressão e interferências nos partidos políticos, sindicatos, agremiações estudantis e outras organizações representativas da sociedade, foram também anos de muita luta pelo reestabelecimento desses direitos. (SANTOS; PEREIRA, 2018, p. 256).

No entanto, embora seja grande o desafio, aguerridos, os representantes sindicais e organizações populares passaram a encampar a luta pela redemocratização da educação no sentido de combater o analfabetismo. Firmes na luta, o país conquistou mais um avanço perseguindo o ideário pela construção de um país livre, com justiça social e ideais de liberdade, desencadeou na aprovação, tanto na Constituição como na Lei de Diretrizes e Bases da Educação Nacional (BRASIL, 1996), onde afirma que educação deve ser inspirada e regida, dentre outros, pelos princípios de liberdade, pluralismo de ideias e concepções pedagógicas, gestão democrática e qualidade.

\section{DIFERENÇAS DE OBJETIVOS DA ESCOLA PÚBLICA ATUAL E A ESCOLA CÍVICO-MILITAR}

Retomar os princípios da Constituição Federal e da Lei de Diretrizes e Bases da Educação Nacional (LDB) é fundamental para que se possa fazer uma análise do posicionamento acerca da escola cívico-militar, que, de acordo com os dois documentos citados, representa um retrocesso social. A implantação deste modelo de espaço educativo fere princípios básicos como a liberdade, o pluralismo de ideias e concepção pedagógica, gestão democrática e qualidade. $\mathrm{Na} \mathrm{LDB}$, ao dispor sobre a organização da educação, é estabelecido no Art. 14, que "os sistemas de ensino definirão as normas da gestão democrática do ensino público na educação básica, de acordo com as suas peculiaridades" (BRASIL, 1996).

Nossa maior lei educacional ressalta ainda, nos incisos I e II do Art. 14, que nessa definição deve ser garantida a "participação dos profissionais da educação na elaboração do projeto pedagógico da escola; e a participação das 
comunidades escolar e local em conselhos escolares ou equivalentes" (BRASIL, 1996).

A escola-cívico militar que o Ministério da Educação (MEC) pretende implantar no país está na contramão dos princípios e diretrizes assegurados nas leis nacionais, pois transfere a gestão das instituições escolares sob a responsabilidade dos seus sistemas de ensino para a Polícia Militar. Tal prática está em discordância com o princípio da gestão democrática e desconsideram o Art. 15 da LDB, que define que os sistemas de ensino devem assegurar às unidades escolares públicas de educação básica sob sua jurisdição "progressivos graus de autonomia pedagógica e administrativa e de gestão financeira, observadas as normas gerais de direito financeiro público" (BRASIL, 1996).

O estado do Goiás foi um dos primeiros a adotar o modelo de escola cívico-militar no Brasil e conta com cerca de 50.000 estudantes submetidos a este regime (GOIÁS, 2015). Ao analisar um trecho do Regimento Interno de uma unidade escolar, cuja gestão é de responsabilidade do Comando da Polícia Militar do Estado de Goiás (CPMG), notamos o reconhecimento da possibilidade de Associações de Pais e Mestres, mas, mesmo assim condiciona que:

Art. 69. Uma vez eleita a nova diretoria, esta deverá ser submetida à apreciação para homologação pelo Comando e Direção do CPMG. $\S 1$ o Em caso de inobservância das prescrições desta seção, o CPMG não reconhecerá a legitimidade representativa da ASPM e será dissolvida por ato do Comandante e Diretor.

Mesmo as associações representativas da comunidade escolar sendo eleitas de forma democrática, elas são submetidas às ordens do comandante, que terá autonomia para dissolvê-las se julgar necessário. Ou seja, a gestão escolar compartilhada com a Policia Militar passa a ser unilateral, a democracia inexiste e abre espaço ao autoritarismo. Cabe a um comandar aos demais membros da comunidade escolar apenas acatar a tomada das decisões (SANTOS; PEREIRA, 2018).

Os autores supracitados realizam um comparativo entre a LDB e o Regimento Interno do CPMG, conforme o Quadro 1. 


\begin{tabular}{|l|l|}
\hline REGIMENTO INTERNO DO CPMG & LDB 9.394 /1996 \\
Art. 4 $4^{\circ}$ O ensino ministrado será & Art. $3^{\circ}$ O ensino será ministrado com base \\
baseado nos seguintes princípios, fins & nos seguintes princípios: \\
e objetivos: & I - Igualdade de condições para o acesso e \\
I - Igualdade de condições para o & permanência na escola; \\
acesso e permanência na escola, & II - Liberdade de aprender, ensinar, pesquisar \\
dentro das normas previstas neste & e divulgar a cultura, o pensamento, a arte e o \\
Regimento; & saber; \\
II - Liberdade de aprender, ensinar, & III - Pluralismo de ideias e de concepções \\
pesquisar e divulgar a cultura, o & pedagógicas; \\
pensamento, a arte o o saber; & IV - Respeito à liberdade e apreço à tolerância; \\
III - Pluralismo de ideias e de & V - Coexistência de instituições públicas e \\
concepções pedagógicas; & privadas de ensino; \\
IV - Respeito à liberdade e apreço à & VI - Gratuidade do ensino público em \\
tolerância; & estabelecimentos oficiais; \\
V - Valorização do profissional da & VII - Valorização do profissional da educação \\
educação escolar; & escolar; \\
VI - Garantia de padrão de qualidade; & VIII - Gestão democrática do ensino público, \\
VII - Valorização da experiência extra- & na forma desta Lei e da legislação dos \\
escolar; & sistemas de ensino; \\
VIII - Vinculação entre educação & IX - Garantia de padrão de qualidade; \\
escolar, o trabalho e as práticas sociais; & X - Valorização da experiência extra-escolar; \\
IX - Gestão democrática do ensino & XI - Vinculação entre a educação escolar, o \\
público, na forma da lei e da legislação \\
do ensino deste CPMG.
\end{tabular}

Fonte: Santos e Pereira (2018, p. 263).

O Quadro 1 evidencia a dicotomia entre a LDB e o regimento interno da escola CPMG, principalmente quando se refere a participação da comunidade escolar na tomada de decisões. Em relação ao administrativo, a escola pública atual respeita os princípios da gestão democrática, enquanto no CPMG a escola obedece aos princípios da disciplina e da ordem. Assim, alguns agentes são membros natos da gestão, ou seja, a gestão destes estabelecimentos de ensino é parcialmente democrática. Outro fator relevante que pode ser destacado no quadro acima é o endurecimento das regras voltadas à disciplinas e em muitos aspectos comprometendo a liberdade de expressão normatizando o comportamento do estudante em face de seu pleno desenvolvimento.

Além disso, o modelo da escola cívico-militar não garante a gratuidade do ensino ofertado, sendo que são cobradas taxas de matrículas, uniformes, e para ingressar na instituição o estudante é submetido a um teste seletivo. Portanto ela é excludente e propõe acentuar as desigualdades sociais. O Sindicato dos Trabalhadores do Ensino Público de Mato Grosso (SINTEP/ 
MT) defende uma escola inclusiva que acolhe e não uma escola que escolhe nesse sentido firma sua defesa em prol de uma escola pública, de qualidade e gratuita para todos.

\section{ACONTECIMENTOS E LUTAS ENFRENTADAS EM MATO GROSSO}

A Lei Estadual no 10.922/2019, visa à implantação do o programa de gestão compartilhada para a criação ou transformação de unidades escolares da rede pública de ensino no estado de Mato Grosso em unidades de gestão compartilhada cívico-militar (MATO GROSSO, 2019). O Deputado Estadual Silvio Favero (PSL), que a propôs, é enfático na defesa da militarização das escolas e percorre o Estado para difundir seu posicionamento e incentivar a sociedade para que seja acelerada a implantação em escolas já existentes.

No mês de dezembro de dois mil e dezenove, reuniram-se nas dependências da Câmara Municipal de Vila Rica/MT, a 1.300 Km de Cuiabá/ MT, o referido deputado com alguns munícipes ${ }^{4}$, convidados por meio de carro de som que circulou na cidade anunciando. A divulgação anunciava que a secretaria municipal de educação estava realizando uma audiência pública sobre a implantação de uma escola militar no município, inclusive informava que todas as pessoas teriam a oportunidade de se inscrever para poder falar.

Um fato que chamou a atenção é que a mesa foi composta por diversos segmentos sociais, em face a ausência do SINTEP/MT, ou de representantes da Escola Estadual Vila Rica. Outra observação é que uma única mulher convidada a compor a mesa foi a Assessora Pedagógica da Secretaria Estadual de Educação (SEDUC/MT) no município. Os demais componentes da mesa eram todos homens, o Deputado Estadual, o Prefeito Municipal como representante do Poder Executivo, o Coronel do $10^{\circ}$ Batalhão da Polícia Militar, o presidente da Câmara de Dirigentes Lojistas (CDL), o presidente da Câmara Municipal, o secretário municipal de educação e um representante do Conselho Comunitário de Segurança Pública (Conseg).

A reunião inicia-se com a exibição de vídeos que demonstraram a indisciplina da escola pública tradicional em face a um vídeo que demonstra a organização e a disciplina da escola militar. Não houve a leitura da Lei Estadual no 10.922/2019, ou a apresentação do projeto/proposta já escrita para Vila Rica, tampouco a realização da audiência com diálogo e deliberações. O referido Deputado, após cumprimentar os presentes, passou a proferir seus posicionamentos pessoais, sem embasamento que comprovasse tais informações, sobre a escola pública e seus profissionais. Seu discurso construiu uma narrativa de que apenas a educação sob o comando dos militares poderá

4 Divulgação na Assembleia Legislativa de Mato Grosso: https://www.al.mt.gov.br/midia/ texto/82/deputado/populacao-de-vila-rica-apoia-implantacao-da-escola-civico-militar/ visualizar 
mudar a sociedade. No decorrer da discussão, quase todos os componentes da mesa reforçaram a urgência de trazer a escola cívico-militar ao município.

A única que destoou desse discurso foi a Assessora Pedagógica da SEDUC, que apresentou os dados do Índice de Desenvolvimento da Educação Básica (IDEB) das duas Escolas Estaduais em funcionamento no município, mostrando que estão acima da meta. Assim, sua defesa foi de que as escolas estão cumprindo a finalidade, o que não foi bem recebido pelos integrantes da mesa. A Assessora e demais professores presentes não foram contra a implantação da escola cívico-militar no município, pelo contrário, a defesa foi no sentido de implantar uma nova escola, o que foi refutado pelos idealizadores do ato.

Boa parte da plateia foi constituída por integrantes da elite da cidade e por simpatizantes políticos do partido do Deputado (PSL). Cabe ressaltar que houve mínima presença de pais de estudantes da rede pública de ensino e alguns professores, que se inscreveram para falar na referida reunião, porém nem todos tiveram a oportunidade. Os professores que se manifestaram defenderam a escola pública nos moldes como está, porém, foram unânimes em ressaltar a falta de investimento do poder público. Em contrapartida, muitos integrantes da plateia começam a desrespeitar o poder de fala daqueles que entendem e que fazer a educação de fato a acontecer por meio de vaias e ofensas, principalmente nos momentos em que professoras mulheres se manifestavam.

Devido aos tumultos provocados pelos partidários e simpatizantes que não conseguiam sequer escutar o contraditório, a audiência foi interrompida inúmeras vezes. A própria diretora da Escola Estadual Vila Rica teve sua fala interrompida. Entre o público presente, muitos defenderam a implantação da escola militar na cidade, mesmo que numa escola já existente. No término da reunião, o secretário municipal de educação apresentou e entregou ao Deputado, um documento já assinado por ele e pelo Prefeito Municipal, o qual solicitava a militarização da Escola Estadual Vila Rica. Isso mostrou a real intenção desse ato que não era consultivo como foi anunciado e um certo desconhecimento sobre as competências de cada esfera.

Ao constatar que a audiência foi meramente uma tentativa de validar um documento já elaborado pelo Poder Executivo, sem a consulta da comunidade escolar, os representantes daquela escola optaram por levar o debate para a sua comunidade escolar, com o intuito de entender o objetivo da audiência envolvendo a Lei Estadual $\mathrm{n}^{\circ}$ 10.922/2019. Em assembleia, a comunidade escolar decidiu pela não militarização da escola, devido as seguintes justificativas: Restrição no atendimento da escola, que também perderia número na oferta de vagas, pois a escola cívico-militar atende somente a partir do sexto ano do Ensino Fundamental até o Ensino Médio; Inviabilidade de atender a educação especial e os estudantes das salas anexas, que ficam nas comunidades rurais; Localização geográfica da escola desfavorável, por ser no Setor Oeste, ou seja, 
os estudantes teriam que atravessar a BR 158, e aqueles entre a faixa etária de 6 a 11 anos de idade, moradores do bairro, teriam que realizar a travessia para serem atendidos em outra escola.

Outro aspecto debatido na assembleia foi a decisão da SEDUC/MT, que por meio do Ofício de $\mathrm{n}^{\circ} 3117 / 2019-\mathrm{GAB} / \mathrm{SEDUC}$, também trata da implantação das escolas cívico-militares. O documento levanta aspectos da referida Lei Estadual, que estão em desacordo com as políticas educacionais vigentes no Estado de Mato Grosso. Entre eles, podemos citar a realização de seletivo e eventuais cobranças de matrícula e compra de uniforme, despesas com as quais muitas famílias brasileiras não podem arcar.

Após a realização da assembleia, a comunidade se posicionou pela não militarização da escola, o que foi registrado por meio de Ata, protocolada nos seguintes órgãos municipais: Assessoria Pedagógica da SEDUC, Câmara Municipal, Ministério Público e no âmbito estadual junto ao SINTEP, SEDUC, gabinete do governador Mauro Mendes, vice governador Otaviano Pivetta e na Assembleia Legislativa, nos gabinetes dos respectivos Deputados Estaduais Ludio Cabral, Tiago Silva e Valdir Barranco, que é presidente da comissão de educação desta instituição legislativa. Também foi levada à esfera nacional, por meio do protocolo no gabinete da Deputada Federal Rosa Neide e encaminhado a então Procuradora Federal dos Direitos do Cidadão (PFDC), senhora Deborah Duprat.

Diante da luta encapada por representantes sindicais, foi possível ampliar o alcance da discussão para as esferas estaduais e federais. Mesmo vivendo em um país democrático no qual somos livres para defender nossos ideais, muitos intolerantes intensificam ataques nas redes sociais a professores que tiveram posicionamento contrário à implantação da escola cívicomilitar em instituições já existentes. Esse movimento de ódio e intolerância foi articulado por lideranças políticas locais, os quais também coletaram assinaturas para compor um baixo assinado para ser entregue ao Governador do Estado, solicitando a militarização da escola existente. Assim como em outros municípios do estado de Mato Grosso, em Vila Rica a luta continua para que as escolas públicas existentes continuem livres e democráticas.

\section{CONSIDERAÇÕES FINAIS}

O propósito deste texto foi realizar uma reflexão histórica sobre como esse preocupante fenômeno vem acontecendo no Sistema Educacional Brasileiro, bem como sobre as recentes lutas em torno da militarização que aconteceram em Mato Grosso. O estudo teórico possibilitou compreender o contexto, geográfico e social do Brasil, que resultou na implantação e estabelecimento do sistema educacional brasileiro. Além desse retrospecto histórico, também foi possível verificar as mudanças na estrutura e organização das escolas brasileiras. 
Um outro aspecto levantado no texto foi sobre as principais diferenças de objetivos da escola pública atual, pautada na gestão democrática e pluralismo de ideias, e a escola cívico-militar, pautada na disciplina e na ordem. Esse estudo também possibilitou relatar e refletir sobre os últimos acontecimentos de lutas contra ataques à educação em Mato Grosso, dando destaque ao enfrentamento à Lei Estadual de n ${ }^{\circ} 10.922 / 2019$, que idealiza militarizar escolas públicas já existentes.

Cabe esclarecer que jamais seremos contra a implantação de novas escolas, sejam elas cívico-militar ou não, o que defendemos é que a escola pública existente, que foi uma conquista social, permaneça livre e democrática, exercendo sua função transformadora e emancipatória na formação humana. Enfim, é importante que a sociedade compare e analise os dois projetos de escola (cívico-militar e a atual) para compreender que uma delas, que não inclui a todos, propõe a disciplina e a ordem como bandeiras, enquanto a outra defende e acolhe todos como sujeitos de direitos, de livre pensamento, capazes de se transformar e mudar a sociedade.

\section{AGRADECIMENTOS}

Aos professores que atuam na rede estadual de ensino de Vila Rica/ MT, que enfrentam com coragem os ataques antidemocráticos, ocasionados por essa situação. À professora Claudia Eliane Zortea, pela realização da revisão linguística.

\section{REFERÊNCIAS}

ABICALIL, Carlos Augusto. O federalismo e o Sistema Nacional de Educação Uma oportunidade fecunda. Revista Retratos da Escola, Brasília, v. 6, n. 10, p. 21-37, jan./ jun. 2012.

BRASIL. Constituição da República Federativa do Brasil. Brasília, DF: Senado Federal, 1988.

. Lei $\mathbf{n}^{\circ}$ 9.394, de 20 de dezembro de 1996. Estabelece as diretrizes e bases da educação nacional.

DUARTE, Alessandra. Repressão da ditadura militar também invadiu as salas de aula: perseguição a professores inclui escutas em escola, demissões e censuras a docentes. Rio de Janeiro: O Globo, 2014. Disponível em: <http:/ /oglobo.globo.com/ sociedade/educacao/repressao-da-ditadura-militar-tambem-invandiu-as-salas-deaula-11896867\#ixzz3T344YFWw>. Acesso em: Jan. 2020.

FIGUEIREDO, Adma Hamam de. Brasil: uma visão geográfica e ambiental no início do século XXI. IBGE. Rio de Janeiro, 2016. 
FREIRE, Paulo. Política e educação: ensaios / Paulo Freire. - 5. ed - São Paulo, Cortez, 2001.

FREIRE, Paulo. Pedagogia do oprimido. Rio de Janeiro: Paz e Terra, 2005.

GERMANO, José Willington. As quarenta horas de Angicos. Educação \& Sociedade, ano XVIII, no 59 , agosto/97.

GUIRALDELLI JR. P. Filosofia e História da Educação Brasileira. Barueri, SP: Manoli, 2003.

GOIÁS. Secretaria de Segurança Pública. Regimento Interno do Colégio da Polícia Militar Do Estado De Goiás. Goiânia, 2015. Disponível em: <https:/ /www.

cpmganapolis.net/wp-content/uploads/2015/05/regimento_interno.pdf >. Acesso em: jan. 2020.

LEDESMA, Maria Rita Kaminski. Evolução histórica da educação brasileira. Guarapuava: Ed. da Unicentro, 2010.

LUCKESI, Cipriano Carlos. Filosofia da Educação. São Paulo: Cortez, 1994. - (Coleção magistério $2^{\circ}$ grau. Série formação do professor).

MATO GROSSO. Lei $\mathbf{n}^{\mathbf{0}} \mathbf{1 0 . 9 2 2 / 2 0 1 9}$. Disponível em: https:/ /www.al.mt.gov.br/ legislacao $/$ ?tipo $=\&$ restringeBusca $=$ e\&palavraChave $=\&$ numeroNorma $=10922 \& a n o-$ Norma $=2019 \&$ autor $=$ Silvio $+F \% C 3 \% A 1$ vero\&dataInicio $=\&$ dataFim $=\& \operatorname{cod}$ Assunto $=\&-$ search. Acesso em: 20 abr. 2020.

MELO, Josimeire Medeiros Silveira de. História da Educação no Brasil / 2 ed. Fortaleza: UAB/IFCE, 2012.

PAIVA, José Maria de. Transmitindo cultura: a catequização dos índios do Brasil, 1549-1600. Revista Diálogo Educacional - v. 1 - n.2 - p.1-170 - jul./dez. 2000.

SANTOS, Catarina de Almeida; PEREIRA, Rodrigo da Silva. Militarização e Escola Sem Partido: Duas faces de um mesmo projeto. Revista Retratos da Escola, Brasília, v. 12, n. 23, p. 255-270, jul./out. 2018. Disponível em: <http//www.esforce.org.br> acessado 07.01.2020.

SAVIANI, Dermeval; ALMEIDA, J. S.; SOUZA, R. F. de; VALDEMARIN, V. T. O legado educacional do século XX no Brasil. Campinas: Autores Associados, 2006, p. 33-57.

Dermeval. História das ideias pedagógicas no Brasil. Campinas, SP: Autores Associados, 2007.

SHIGUNOV NETO, A.; MACIEL, L. S. B. O ensino jesuítico no período colonial brasileiro: algumas discussões. Revista Educar, Curitiba: Editora UFPR, n. 31, p. 169189, 2008. 
VEIGA, Ilma Passos (coord.). Repensando a Didática. Campinas: Papirus,1989.

VICENTINI, Paula Perin, LUGLI, Rosário Genta. História da Profissão Docente no Brasil: Representações em Disputa. Cortez Editora, 2009.

VIDAL, Diana Gonçalves. 80 anos do Manifesto dos Pioneiros da Educação Nova: questões para debate. Educ. Pesqui., São Paulo, v. 39, n. 3, p. 577-588, jul./set. 2013. Disponível em: https://www.al.mt.gov.br/storage/webdisco/ cp/20190328094257152100.pdf Acesso em: 20 abr. 2020. 